\title{
Use of metformin during pregnancy for women with polycystic ovary syndrome
}

\author{
Howard Fan \\ University of New South Wales, Sydney, Australia \\ Email: howard.fan@student.unsw.edu.au
}

Received 26 November 2012; revised 28 December 2012; accepted 8 January 2013

\begin{abstract}
Objective: The purpose of this article is to review the literature assessing foetal and maternal pregnancy outcomes in women with PCOS who used metformin during pregnancy. Study Design: A literature search was conducted using MEDLINE, with analysis of 25 studies that recorded neonatal and maternal outcomes in women who used metformin during pregnancy. The outcomes assessed in this review include congenital deformities, miscarriages, preterm labour, gestational diabetes (GDM) and pregnancy induced hypertension (PIH). Results: We found that the use of metformin throughout pregnancy correlated with decreased rates of preterm labour, GDM and PIH. Conflicting evidence exists over whether metformin use during pregnancy reduced miscarriage rates. The use of metformin during pregnancy did not increase teratogenicity risks. Conclusion: The use of metformin throughout pregnancy is associated with decreased rates of preterm labour, GDM, and PIH. However, more randomised controls involving larger numbers of participants are required for more definitive results.
\end{abstract}

Keywords: Metformin; Polycystic Ovary Syndrome; Pregnancy Complications; Pregnancy Outcomes; Miscarriage; Preterm Labour; Gestational Diabetes; Pregnancy Induced Hypertension

\section{INTRODUCTION}

Polycystic ovary syndrome (PCOS) is a condition diagnosed on the satisfaction of at least two of the following three criteria: 1) Oligoovulation or anovulation; 2) Clinical and/or biochemical evidence of hyperandrogenism; 3) Ultrasound findings of polycystic ovaries [1]. Women with PCOS are more likely to be obese and require assisted reproductive technology than women without PCOS [2]. The effects of PCOS on pregnancy remains controversial with some trials showing increased rates of early pregnancy loss (EPL) and foetal congenital abnor- malities, with others showing no significance [3]. More recent studies have shown increased risks of pregnancy induced hypertension (PIH), preeclampsia, gestational diabetes (GDM), preterm labour and small for gestational age (SGA) infants in women with PCOS [4].

Increasingly, insulin sensitising agents have been used to manage women with PCOS. Metformin is a biguanide class antidiabetic with multiple actions. Metformin decreases intestinal absorption of glucose, impairs hepatic gluconeogenesis and stimulates glucose uptake by muscle cells via the glucose transport (GLUT) system to improve peripheral sensitivity of insulin [5]. Metformin does not cause hypoglycaemia but common dose-dependent adverse effects include abdominal discomfort, diarrhoea, nausea, and in rare cases, lactic acidosis [6].

In women with PCOS, metformin reduces insulin resistance, improves hyperandrogenemia and normalises menstrual abnormalities independent of weight loss. These improvements were most evident in women with insulin resistance, lower serum androstenedione levels, and less severe menstrual abnormalities [7]. Metformin is increasingly being used as an ovulation induction agent, either alone or with clomiphene, to improve ovulation rates [8]. However, a recent Cochrane review of randomised controlled trials found that although using metformin for ovulation induction improved pregnancy rates, it did not reduce miscarriage rates and did not result in higher live birth rates [9]. The question still remains regarding whether continuing metformin throughout pregnancy would offer additional benefits. The purpose of this review is to assess the use of metformin during pregnancy.

\section{METHODS}

A MEDLINE-based literature search, which included articles between the years of 1946 and 2012, was conducted using the following search criteria: exp *polycystic ovary syndrome/AND exp *metformin/AND (exp *pregnancy outcomes/OR exp *pregnancy complications/OR exp *abortions, spontaneous/). A total of 57 articles were assessed for analysis with relevant refer- 
ences from these articles manually searched and included in the analysis. Review articles, editorial pieces, duplicates and trials that did not continue metformin during pregnancy, were excluded.

\section{RESULTS}

Of the 25 trials included for this review, there were four randomised controlled trials (RCTs) [10-13], one clinical trial [14], four retrospective cohort studies [15-18], and sixteen prospective cohort studies [19-34]. These studies were conducted globally with a large number originating from USA. Metformin was limited to the first trimester in four trials $[11,14,16,27]$, with the remainder continuing metformin for the entire duration of pregnancy. A comparison of continuing metformin in the first trimester and throughout pregnancy was made in four trials [10,23,26,33]. Metformin was used for fertility treatment in most participants prior to pregnancy. Apart from one prospective study where metformin was reduced by a third throughout the first trimester [20], all the women treated with metformin for infertility continued their preconception doses throughout pregnancy. Women starting metformin in pregnancy were titrated up from half dose in the first week to full dose for the remainder of the pregnancy [11-13]. The maximum doses of metformin reached $2550 \mathrm{mg}$ daily [19,22,24,28,30,32-34]. The study design and outcomes of the RCTs are summarised in Table 1.

\subsection{Miscarriage Rates}

Fourteen studies assessed the association between metformin and miscarriage rates of women affected by PCOS, with six focusing on EPL. Eleven of these studies showed statistical significance for reduced miscarriages with five studies specifically addressing EPL [15,18,25, $33,34]$ and the remainder being unspecified [14,17,19,20, $23,28]$. The results of six studies were compared against the previous pregnancy results of the participants [14, $17,19,28,33,34]$, and five were compared against control groups with PCOS $[15,18,20,23,25]$. Three studies showed reduced miscarriage rates in women with recurrent pregnancy loss (RPL) $[15,19,28]$ of which two studies combined metformin with enoxaparin [19,28].

Of the remaining three studies, two showed no difference in miscarriage rates with the use of metformin compared to normal populations [11,27], and the remaining RCT showed that continuing metformin throughout pregnancy results in the same miscarriage outcomes as ceasing metformin after eight weeks [10].

\subsection{Preterm Labour}

Seven studies assessed the association of metformin and preterm labour in women with PCOS, of which four showed that metformin statistically reduced preterm labour rates [12,13,20,23]. One RCT showed no difference in preterm labour rates with use of metformin throughout pregnancy compared to eight weeks [10], and one retrospective study showed higher preterm rates compared to normal populations [17].

\subsection{Safety}

None of the studies reported increased neonatal complications, including low birth weight (LBW), neonatal hy-poglycaemia or neonatal unit admissions, associated withthe use of metformin in the first trimester or throughout pregnancy. Follow up studies in infants exposed to met formin during pregnancy showed no dif-

Table 1. Summary of design and outcomes of the included RCTs.

\begin{tabular}{|c|c|c|c|c|}
\hline Study & Study Type & Study Design & $\begin{array}{c}\text { Foetal Outcomes } \\
\text { (Treatment vs. Control) }\end{array}$ & $\begin{array}{c}\text { Maternal Outcomes } \\
\text { (Treatment vs. Control) }\end{array}$ \\
\hline $\begin{array}{l}\text { Morin-Papunen et } \\
\text { al., } 2012 \text { [Finland] }\end{array}$ & $\begin{array}{l}\text { Multi-centre } \\
\text { RCT }\end{array}$ & $\begin{array}{l}320 \text { PCOS patients treated for } 3 \\
\text { months: } \\
160 \text { with metformin } \\
160 \text { with placebo }\end{array}$ & $\begin{array}{l}\text { No difference in miscarriage rates } \\
(15.2 \% \text { vs. } 17.8 \% ; p=0.7)\end{array}$ & $\begin{array}{c}\text { Reduced weight gain }(\mathrm{p}<0.001) \\
\text { Reduced BMI gain }(\mathrm{p}<0.001)\end{array}$ \\
\hline $\begin{array}{c}\text { Vanky et al., } 2010 \\
\text { [Norway] }\end{array}$ & $\begin{array}{l}\text { Multi-centre } \\
\text { RCT }\end{array}$ & $\begin{array}{l}270 \text { pregnancies of PCOS patients } \\
\text { treated throughout pregnancy: } \\
135 \text { with metformin } \\
125 \text { with placebo }\end{array}$ & $\begin{array}{c}\text { Reduced preterm }(<37 \text { weeks }) \\
\text { delivery }(2.8 \% \text { vs. } 10.2 \% \mathrm{p}=0.03)\end{array}$ & $\begin{array}{c}\text { Reduced weight gain }(\mathrm{p}=0.001) \\
\text { No significant reduction in } \\
\text { maternal complications } \\
\text { (pre-eclampsia, GDM) }\end{array}$ \\
\hline $\begin{array}{l}\text { Begum et al., } 2009 \\
\text { [Bangladesh] }\end{array}$ & $\begin{array}{l}\text { Single centre } \\
\text { RCT }\end{array}$ & $\begin{array}{l}59 \text { PCOS patients taking metformin: } \\
30 \text { ceased metformin at } 8 \text { weeks } \\
29 \text { continued metformin throughout } \\
\text { pregnancy }\end{array}$ & $\begin{array}{c}\text { No difference in miscarriage rates } \\
(3.3 \% \text { vs. } 3.3 \%) \\
\text { No difference in preterm labour } \\
(6.88 \% \text { vs. } 10 \%) \\
\text { Lower rates of macrosomia } \\
(0 \% \text { vs. } 13.33 \%)\end{array}$ & $\begin{array}{c}\text { Lower GDM rates } \\
\text { (OR 12; 95\% CI } 6.20-18.08)\end{array}$ \\
\hline
\end{tabular}

*Both miscarriage rates are similar to the general population. 
ference in weight, height, motor-social developments or intercurrent illnesses requiring a paediatrician at 3 and 6 months [24,33].

There was no evidence from any of the trials to suggest that the use of metformin throughout pregnancy resulted in an increased rate of congenital abnormalities compared to the baseline rate. Congenital abnormalities that were recorded in the metformin groups include one case of polydactyly [15], CAH [17], cleft palate [17], Potter's syndrome [17], achondroplasia [18], sacrococcygeal teratoma [22], and tracheoesophageal fistula [25].

\subsection{Pregnancy Induced Hypertension (PIH)}

Five studies investigated the effects of metformin on PIH in women with PCOS. Four of these showed a statistically significant decrease in PIH with the use of metformin throughout pregnancy compared to PCOS and normal populations [15,20,21,23], while one showed an increase in PIH compared to a normal population [26].

\subsection{Gestational Diabetes Mellitus (GDM)}

Thirteen studies assessed the relationship between metformin and GDM in women with PCOS, with nine showing that continuing metformin throughout pregnancy reduced GDM [10,15,20-23,30,32,33]. However, two showed no change [12,31] and two showed increased risk compared to normal populations $[16,26]$. In all the studies, GDM was determined using either a fasting glucose, a glucose challenge test (GCT), or an oral glucose tolerance test (OGTT) between 19 and 32 weeks, depending on the local policy. The use of GCT at 24 - 26 weeks was common [20,22,28,30,32,33], and there was no mention of ceasing metformin prior to these tests in any of the studies.

\subsection{Other Benefits}

Four studies showed that metformin reduced BMI and weight gain [11,12,32,33], while five showed metformin decreased serum insulin levels and insulin resistance [18,29,32-34]. Two studies showed reduced rates of intrauterine growth restriction (IUGR) [15,23]. Metformin was not found to cause major side effects, and no cases of lactic acidosis were reported in any of the studies. Minor side effects associated with metformin, including nausea, diarrhoea, vomiting and abdominal discomfort was more prevalent in one RCT [11].

\subsection{Metformin Use in First Trimester Compared to Entire Pregnancy}

Only four studies compared neonatal outcomes from the use of metformin for the first trimester compared to the entire pregnancy. These studies suggested that longer use of metformin was associated with reduced IUGR [23], preterm labour [23] and macrosomia rates [10], with no difference in subsequent infant growth [33] for the infant as well as improved outcomes in terms of PIH [23] and GDM [10,23] for the mother. However, one RCT did not find statistical significance in preterm labour rates [10] while another prospective study found that compared to a normal population, metformin use in women with PCOS was associated with earlier pregnancy, and increased PIH and GDM rates [26]. Effects on miscarriage are uncertain, with one study showing reduced rates with metformin use throughout pregnancy [23] and another showing no difference [10].

\section{DISCUSSION}

Our analysis revealed inconsistent evidence regarding the effects of continuing metformin throughout pregnancy on miscarriage rates. A series of studies have evidence supporting the role of metformin in reducing miscarriage rates. This was not supported in a recent multicentre RCT, which showed similar miscarriage rates in both the metformin and control group [11]. However, these rates were comparable to background miscarriage rates, which may have been influenced by improved antenatal care. Most of the evidence supporting reduced miscarriage rates was from small scale prospective or retrospective studies, which had low numbers of miscarriages, and did not measure miscarriage as a primary objective. The results were often compared to a healthy population without PCOS or to the results of previous pregnancies, and did not consider confounding factors such as improved antenatal care. All these factors may have contributed to bias in the results.

Evidence for metformin's role in reducing preterm labour is supported by two RCTs $[12,13]$ and two prospective studies [20,23]. Furthermore, there was no increased harm associated with the continuation of metformin. Our analysis did not find a correlation between metformin and increased congenital malformations in neonates. This is consistent with recent studies that showed metformin to be safe in pregnancy for treating GDM [35,36].

There is some evidence supporting maternal benefits of using metformin in women with PCOS in terms of reducing GDM and PIH. Six studies, including one RCT, showed that metformin decreased GDM rates when used throughout pregnancy. This is supported by the reduction in GDM risk factors as presented in five studies showing decreased serum insulin and insulin resistance, and four studies, including two RCTs, showing reduced BMI and weight gain with use of metformin throughout pregnancy. Women on metformin are still recommended to undergo the usual tests for GDM without special considerations and are to be treated for GDM if found positive. Only six studies considered $\mathrm{PIH}$ but four provided evidence for 
metformin decreasing PIH when compared against other women with PCOS and normal populations. The studies that showed no change or increased rates of GDM and PIH did not have well matched controls and were compared to normal populations without PCOS.

In terms of reducing IUGR, preterm labour, PIH and GDM, current studies also suggest that it may be beneficial to continue metformin throughout pregnancy rather than to cease after the first trimester. However, there are not enough direct comparisons between using metformin for the first trimester and the entire pregnancy to establish this correlation.

The main limitation with this review is the lack of large scale RCTs in this area. Due to the lack of a balanced control group, prospective and retrospective trials studies are more prone to random error and confounding bias. These include comparing women with PCOS to normal populations, geographical and racial differences, and access to antenatal care, which may all affect foetal and maternal outcomes.

In conclusion, there is currently some evidence supporting the use of metformin throughout pregnancy for reducing preterm labour, GDM and PIH. However, this area currently lacks investigation from large scale RCTs, and more evidence from such trails are required before more definitive conclusions can be drawn.

\section{ACKNOWLEDGEMENTS}

I would like to thank Dr. Emmanuel Karantanis for his encouragement.

\section{REFERENCES}

[1] Rotterdam, E.A.S.P.C.W.G. (2004) Revised 2003 consensus on diagnostic criteria and long-term health risks related to polycystic ovary syndrome. Fertility \& Sterility, 81, 19-25. doi:10.1016/j.fertnstert.2003.10.004

[2] Roos, N., Kieler, H., Sahlin, L., Ekman-Ordeberg, G., Falconer, H. and Stephansson, O. (2011) Risk of adverse pregnancy outcomes in women with polycystic ovary syndrome: Population based cohort study. British Medical Journal, 343, Article ID: d6309. doi:10.1136/bmj.d6309

[3] Iavazzo, C. and Vitoratos, N. (2010) Polycystic ovarian syndrome and pregnancy outcome. Archives of Gynecology \& Obstetrics, 282, 235-239. doi:10.1007/s00404-010-1495-0

[4] Kjerulff, L.E., Sanchez-Ramos, L. and Duffy, D. (2011) Pregnancy outcomes in women with polycystic ovary syndrome: A metaanalysis. American Journal of Obstetrics \& Gynecology, 204, 558.e1-558e6.

[5] Sirtori, C.R. and Pasik, C. (1994) Re-evaluation of a biguanide, metformin: mechanism of action and tolerability. Pharmacological Research, 30, 187-228. doi:10.1016/1043-6618(94)80104-5

[6] Garber, A.J., Duncan, T.G., Goodman, A.M., Mills, D.J. and Rohlf, J.L. (1997) Efficacy of metformin in type II diabetes: Results of a double-blind, placebo-controlled, dose-response trial. American Journal of Medicine, 103, 491-497. doi:10.1016/S0002-9343(97)00254-4

[7] Moghetti, P., Castello, R., Negri, C., Tosi, F., Perrone, F., Caputo, M., Zanolin, E. and Muggeo, M. (2000) Metformin effects on clinical features, endocrine and metabolic profiles, and insulin sensitivity in polycystic ovary syndrome: A randomized, double-blind, placebo-controlled 6-month trial, followed by open, long-term clinical evaluation. Journal of Clinical Endocrinology \& Metabolism, 85, 139-146. doi:10.1210/jc.85.1.139

[8] Creanga, A.A., Bradley, H.M., McCormick, C. and Witkop, C.T. (2008) Use of metformin in polycystic ovary syndrome: A meta-analysis. Obstetrics \& Gynecology, 111, 959-968. doi:10.1097/AOG.0b013e31816a4ed4

[9] Tang, T., Lord, J.M., Norman, R.J., Yasmin, E. and Balen, A.H. (2012) Insulin-sensitising drugs (metformin, rosiglitazone, pioglitazone, D-chiro-inositol) for women with polycystic ovary syndrome, oligo amenorrhoea and subfertility. Cochrane Database of Systematic Reviews, 5, Article ID: CD003053.

[10] Begum, M.R., Khanam, N.N., Quadir, E., Ferdous, J., Begum, M.S., Khan, F. and Begum, A. (2009) Prevention of gestational diabetes mellitus by continuing metformin therapy throughout pregnancy in women with polycystic ovary syndrome. Journal of Obstetrics \& Gynaecology Research, 35, 282-286. doi:10.1111/j.1447-0756.2008.00876.x

[11] Morin-Papunen, L., Rantala, A.S., Unkila-Kallio, L., Tiitinen, A., Hippelainen, M., Perheentupa, A., Tinkanen, H., Bloigu, R., Puukka, K., Ruokonen, A. and Tapanainen, J.S. (2012) Metformin improves pregnancy and live-birth rates in women with polycystic ovary syndrome (PCOS): A multicenter, double-blind, placebo-controlled randomized trial. Journal of Clinical Endocrinology \& Metabolism, 97, 1492-500. doi:10.1210/jc.2011-3061

[12] Vanky, E., Stridsklev, S., Heimstad, R., Romundstad, P., Skogoy, K., Kleggetveit, O., Hjelle, S., von Brandis, P., Eikeland, T., Flo, K., Berg, K.F., Bunford, G., Lund, A., Bjerke, C., Almas, I., Berg, A.H., Danielson, A., Lahmami, G. and Carlsen, S.M. (2010) Metformin versus placebo from first trimester to delivery in polycystic ovary syndrome: A randomized, controlled multicenter study. Journal of Clinical Endocrinology \& Metabolism, 95, E448-E455. doi:10.1210/jc.2010-0853

[13] Salvesen, K.A., Vanky, E. and Carlsen, S.M. (2007) Metformin treatment in pregnant women with polycystic ovary syndrome-Is reduced complication rate mediated by changes in the uteroplacental circulation? Ultrasound in Obstetrics \& Gynecology, 29, 433-437. doi:10.1002/uog.3965

[14] Sohrabvand, F., Shariat, M., Haghollahi, F. and Bagheri, B. (2009) Effect of metformin on miscarriage in pregnant patients with polycystic ovary syndrome. West Indian Medical Journal, 58, 433-436.

[15] Nawaz, F.H. and Rizvi, J. (2010) Continuation of metformin reduces early pregnancy loss in obese Pakistani women with polycystic ovarian syndrome. Gynecologic \& Obstetric Investigation, 69, 184-189. 


\section{doi:10.1159/000268051}

[16] Bolton, S., Cleary, B., Walsh, J., Dempsey, E. and Turner, M.J. (2009) Continuation of metformin in the first trimester of women with polycystic ovarian syndrome is not associated with increased perinatal morbidity. European Journal of Pediatrics, 168, 203-206. doi:10.1007/s00431-008-0737-7

[17] Thatcher, S.S. and Jackson, E.M. (2006) Pregnancy outcome in infertile patients with polycystic ovary syndrome who were treated with metformin. Fertility \& Sterility, 85, 1002-1009. doi:10.1016/j.fertnstert.2005.09.047

[18] Jakubowicz, D.J., Iuorno, M.J., Jakubowicz, S., Roberts, K.A. and Nestler, J.E. (2002) Effects of metformin on early pregnancy loss in the polycystic ovary syndrome. Journal of Clinical Endocrinology \& Metabolism, 87, 524-529. doi:10.1210/jc.87.2.524

[19] Ramidi, G., Khan, N., Glueck, C.J., Wang, P. and Goldenberg, N. (2009) Enoxaparin-metformin and enoxaparin alone may safely reduce pregnancy loss. Translational Research: The Journal of Laboratory \& Clinical Medicine, 153, 33-43. doi:10.1016/j.trsl.2008.11.003

[20] De Leo, V., Musacchio, M.C., Piomboni, P., Di Sabatino, A. and Morgante, G. (2011) The administration of metformin during pregnancy reduces polycystic ovary syndrome related gestational complications. European Journal of Obstetrics, Gynecology, \& Reproductive Biology, 157, 63-66. doi:10.1016/j.ejogrb.2011.03.024

[21] Khattab, S., Mohsen, I.A., Aboul Foutouh, I., Ashmawi, H.S., Mohsen, M.N., van Wely, M., van der Veen, F. and Youssef, M.A. (2011) Can metformin reduce the incidence of gestational diabetes mellitus in pregnant women with polycystic ovary syndrome? Prospective cohort study. Gynecological Endocrinology, 27, 789-793. doi:10.3109/09513590.2010.540600

[22] Glueck, C.J., Pranikoff, J., Aregawi, D. and Wang, P. (2008) Prevention of gestational diabetes by metformin plus diet in patients with polycystic ovary syndrome. Fertility \& Sterility, 89, 625-634. doi:10.1016/j.fertnstert.2007.03.036

[23] Nawaz, F.H., Khalid, R., Naru, T. and Rizvi, J. (2008) Does continuous use of metformin throughout pregnancy improve pregnancy outcomes in women with polycystic ovarian syndrome? Journal of Obstetrics \& Gynaecology Research, 34, 832-837. doi:10.1111/j.1447-0756.2008.00856.x

[24] Glueck, C.J., Salehi, M., Sieve, L. and Wang, P. (2006) Growth, motor, and social development in breast- and formula-fed infants of metformin-treated women with polycystic ovary syndrome. Journal of Pediatrics, 148, 628-632. doi:10.1016/j.jpeds.2006.01.011

[25] Khattab, S., Mohsen, I.A., Foutouh, I.A., Ramadan, A., Moaz, M. and Al-Inany, H. (2006) Metformin reduces abortion in pregnant women with polycystic ovary syndrome. Gynecological Endocrinology, 22, 680-4. doi:10.1080/09513590601010508

[26] Kovo, M., Weissman, A., Gur, D., Levran, D., Rotmensch, S. and Glezerman, M. (2006) Neonatal outcome in polycystic ovarian syndrome patients treated with metformin during pregnancy. Journal of Maternal-Fetal
\& Neonatal Medicine, 19, 415-419. doi:10.1080/14767050600682370

[27] Turner, M.J., Walsh, J., Byrne, K.M., Murphy, C., Langan, H. and Farah, N. (2006) Outcome of clinical pregnancies after ovulation induction using metformin. Journal of Obstetrics \& Gynaecology, 26, 233-235. doi:10.1080/01443610600555295

[28] Glueck, C.J., Wang, P., Goldenberg, N. and Sieve, L. (2004) Pregnancy loss, polycystic ovary syndrome, thrombophilia, hypofibrinolysis, enoxaparin, metformin. Clinical \& Applied Thrombosis/Hemostasis, 10, 323-334. doi:10.1177/107602960401000404

[29] Glueck, C.J., Goldenberg, N., Wang, P., Loftspring, M. and Sherman, A. (2004) Metformin during pregnancy reduces insulin, insulin resistance, insulin secretion, weight, testosterone and development of gestational diabetes: prospective longitudinal assessment of women with polycystic ovary syndrome from preconception throughout pregnancy. Human Reproduction, 19, 510-521. doi:10.1093/humrep/deh109

[30] Glueck, C.J., Goldenberg, N., Pranikoff, J., Loftspring, M., Sieve, L. and Wang, P. (2004) Height, weight, and motor-social development during the first 18 months of life in 126 infants born to 109 mothers with polycystic ovary syndrome who conceived on and continued metformin through pregnancy. Human Reproduction, 19, 1323-1330. doi:10.1093/humrep/deh263

[31] Glueck, C.J., Bornovali, S., Pranikoff, J., Goldenberg, N., Dharashivkar, S. and Wang, P. (2004) Metformin, preeclampsia, and pregnancy outcomes in women with polycystic ovary syndrome. Diabetic Medicine, 21, 829-836. doi:10.1111/j.1464-5491.2004.01251.x

[32] Glueck, C.J., Wang, P., Kobayashi, S., Phillips, H. and Sieve-Smith, L. (2002) Metformin therapy throughout pregnancy reduces the development of gestational diabetes in women with polycystic ovary syndrome. Fertility \& Sterility, 77, 520-525. doi:10.1016/S0015-0282(01)03202-2

[33] Glueck, C.J., Wang, P., Goldenberg, N. and Sieve-Smith, L. (2002) Pregnancy outcomes among women with polycystic ovary syndrome treated with metformin. Human Reproduction, 17, 2858-2864. doi:10.1093/humrep/17.11.2858

[34] Glueck, C.J., Phillips, H., Cameron, D., Sieve-Smith, L. and Wang, P. (2001) Continuing metformin throughout pregnancy in women with polycystic ovary syndrome appears to safely reduce first-trimester spontaneous abortion: A pilot study. Fertility \& Sterility, 75, 46-52. doi:10.1016/S0015-0282(00)01666-6

[35] Rowan, J.A., Hague, W.M., Gao, W., Battin, M.R., Moore, M.P. and Mi, G.T.I. (2008) Metformin versus insulin for the treatment of gestational diabetes. New England Journal of Medicine, 358, 2003-2015. doi:10.1056/NEJMoa0707193

[36] Moore, L.E., Briery, C.M., Clokey, D., Martin, R.W., Williford, N.J., Bofill, J.A. and Morrison, J.C. (2007) Metformin and insulin in the management of gestational diabetes mellitus: Preliminary results of a comparison. Journal of Reproductive Medicine, 52, 1011-1015. 